\title{
Pharmaceutical Care as Described by Home-Dwelling Older People in Finland
}

\author{
Sini Eloranta ${ }^{1,2}$, Sanna Hannukainen ${ }^{1,3}$, Pirkko Routasalo ${ }^{4}$, Matti Viitanen ${ }^{5}$, Seija Arve ${ }^{1,3}$ \\ ${ }^{1}$ Turku City Hospital, ${ }^{2}$ The Age Institute, Helsinki, ${ }^{3}$ Department of Nursing Science, University of Turku, \\ ${ }^{4}$ Department of Clinical Medicine, University of Helsinki, ${ }^{5}$ Department of Geriatrics, University of Turku, Finland
}

Key words: interview study; older people; pharmaceutical care at home.

Summary. Background and Objective. Pharmaceutical care is one of the most important therapeutic tools in older people care. The aim of this study was to describe the knowledge and attitudes of older home-dwelling people's about their perceptions of pharmaceutical care and use of medication.

Material and Methods. The data were collected using theme interviews with 16 older Finnish people (born 1920). Inductive content analysis was used in analyzing the data.

Results. Older people's knowledge about their pharmaceutical care varied widely: some had precise knowledge whereas others had none. Guidance in pharmaceutical care was not readily available. The interviewees took a positive attitude toward their pharmaceutical care and favored a minimum use of medication. Being able to cope independently with their pharmaceutical care strengthened the older people's sense of control over their lives.

Conclusions. The study offers new knowledge about the significance of older people's individual pharmaceutical care at home. By listening to and utilizing older people's experiences, we can recognize the factors that promote the independent coping and inclusion of older people in their pharmaceutical care. This enables health care providers to increase the safety and quality of pharmaceutical care for older people.

\section{Introduction}

Pharmaceutical care is one of the most important therapeutic tools in older people's care (1). However, the prevalence of polypharmacy among the older population is significant. Many older people live alone and do not have adequate supervision in medication (2). Excessive polypharmacy is associated with a decline in functional ability and cognitive capacity (3). Of the home-dwelling Finnish older people ( $\geqslant 75$ years), almost all $(99 \%)$ use at least one drug, and the average number of drugs used is about $7(3,4)$. Pharmaceutical care brings quality of life and welcome relief to older people, whereas adverse drug events are important causes of illness and death in this group (1).

Older people's attitudes toward their pharmaceutical care have been quite positive (5-7). Knowledge about personal medication and its possible side effects as well as trust in medication have helped the older people's commitment to medication (7-9). Older people trust their doctors' expertise in medication. In spite of this, older people feel that they are personally responsible for their drug use. However, for example, in Finnish home care, general practitioners and home care nurses make the care plans together, without the participation of older people themselves (10).

Correspondence to S. Eloranta, Turku City Hospital, Finland, P.O. Box 355, 20101 Turku, Finland. E-mail: sinelo@utu.fi
Of the older people with long-term illnesses, about half used medication according to doctor's orders, and the other half either discontinued their medication or took their drugs irregularly $(11,12)$. The risk factors in the pharmaceutical care of older people were often connected with changing routines in the administration of drugs or confusion in the trade name and the name of the drug (13). It has also been reported that polypharmacy can occur with older people suffering from problems of health, nutrition, functional capacity, or cognition (3). Forgetfulness is one of the problems associated with older people's pharmaceutical care. Older people may have difficulties in remembering the directions in administration or they forget to take their medication. This was especially problematic with Swedish people living alone who had memory problems and who only received home help for once a week with a home nurse delivering their drugs in a dispenser. In these situations, the pharmaceutical care of the older people was in their own hands (7). Although the use of medication among older people has increased, very little is still known about pharmaceutical care as described by older people themselves. The aim of this study was to describe the knowledge and attitudes of older home-dwelling people and their perceptions of pharmaceutical care and use of medication. 


\section{Material and Methods}

Design. A qualitative design using theme interviews was chosen as the most appropriate method for addressing the research question. As Seidman (14) states, interviews are used to help researchers understand the experience of participants, the meanings these experiences hold, and the context in which these realities are developed and resolved.

The Aim and Objectives. The aim of the study was to describe the knowledge and attitudes of older home-dwelling people and their perceptions of pharmaceutical care and use of medication. The objectives of this study were to describe the following issues:

1. What do older people know about their pharmaceutical care?

2. What kind of attitudes do older people have concerning their pharmaceutical care?

3. How is the pharmaceutical care of older people carried out at home?

Participants. This study is a part of The Turku Aging Study, which was a prospective, populationbased, 15-year follow-up study of the age cohort of 70-year olds (born 1920) living in the city of Turku (population 177 000), Finland. The baseline measurements were conducted in 1991 and the followup measurements in 2001 and 2006 (15). The target group of the study was selected from the participants of the 2006 follow-up study $(n=276)$ according to the following criteria: 1) voluntary participation in the study, 2) a regular use of at least 5 medicines, and 3) being able to discuss everyday matters in a coherent way, oriented in place and time (a score of the Mini-Mental State Examination of at least 24). Persons meeting the criteria included 112 participants of whom 20 persons were chosen. The nonprobability sample of participants aimed to find male and female subjects who included receivers and nonreceivers of home nursing and who had experience of pharmaceutical care. A covering letter inquiring their willingness to participate in the study was mailed to the target group. Sixteen participants (born 1920) returned the signed covering letters. There were 11 women and 5 men. Thirteen of them lived alone, two together with a spouse, and one lived together with a son. Six participants needed home care in order to cope with the activities of daily living.

Data Collection. The data were collected in 2007; the personnel working in The Turku Aging Study acted as contact persons. At first, the participants were approached with a covering letter, delivered by the contact person to those who met the study criteria and who were willing to participate and share their experiences. The covering letter explained the aims of the study and the method of implementa- tion. The participants were also told where they could get additional information if needed. Voluntary participants returned the signed covering letters, along with their contact information to the researcher via the personnel working in home services. Eventually, the researcher contacted the subjects by telephone and arranged interviews in their homes. At the beginning of the interview, the researcher once more explained the aims of the study, the voluntary nature of their participation, and the possibility to withdraw from the study at any time to the interviewee.

The data were collected through theme interviews (16). The theme interview outline contained 3 themes according to the study objectives: knowledge of pharmaceutical care, attitudes concerning pharmaceutical care, and pharmaceutical care at home. The interviews resembled conversation and progressed on the interviewees' terms, while the researcher presented specifying questions in accordance with the research aims. The researcher encouraged the interviewees to talk about their experiences as openly as possible in their own words. The interviews lasted between 20 and 50 minutes. The interviews were recorded with the consent of the interviewees. The researcher also kept a diary where notes were entered on the ambience of the conversation as well as general impressions of the interview. In addition, notes that critically examined interviewing performance during the course of the interview were maintained. After the interview, the researcher transcribed the material. The amount of text totaled 69 pages (line spacing 1).

Data Analysis. The data were analyzed through the methods of qualitative inductive content analysis. The analysis was initiated during the data collection phase. A sentence or part of a sentence containing a term or phrase central to the research problem was chosen as the unit of analysis. The interviews were read several times in order to achieve data immersion. The inductive content analysis was carried out step by step as the data were conceptualized (17). The data were primarily simplified through searching the transcribed material for terms and phrases describing the research questions. The data analysis continued until no new information could be found.

Ethical Considerations. Appropriate permissions were obtained from the organizations concerned. All participants were informed both orally and in writing that participation was voluntary and that they had a right to withdraw at any time. Written informed consent was obtained from all participants, and all information was treated confidentially. 


\section{Results}

Knowledge of Pharmaceutical Care. Of the interviewees, the average number of drugs used was about 7 ( 7.5 for women and 6.8 for men). The most common drugs included beta-blockers, salicylic acid, glyceryl trinitrate, lipid-lowering drugs, and diuretics. The interviewees who had had the same medication for years remembered their illnesses and drugs quite well. Some knew only some of the drugs or what illnesses they had been prescribed for. Some knew what illnesses their drugs were for, but they did not know the names of the drugs. Some of the interviewees had a list of medication made at the pharmacy, or they had written down a list for themselves. By going through the lists, they could remember what drugs they had to take for each illness. There were also some interviewees who were not aware of their illnesses or what drugs they had been prescribed. Home nurses took care of the medication of these people.

The interviewees who took care of their own medication had received guidance in pharmaceutical care from their doctors when the drugs had been prescribed. The interviewees had also received guidance from home nurses and pharmacies. People wanted more guidance in situations when new drugs were prescribed and when health or memory problems emerged. Two participants hoped for more guidance from their doctors, and one participant thought that he could no longer influence his care in any way. This participant received home nursing and daily home help. One-third of the participants reported that they had not received any guidance in pharmaceutical care except by reading the informative label of the drug: "I have read the instructions in the package" and "I have no idea about my drugs, I am dependent on others."

Attitudes Concerning Pharmaceutical Care. The majority of interviewees had a positive attitude toward pharmaceutical care, which was considered a part of everyday routines. They reported that it was necessary to use the medication prescribed by the doctor in order to maintain functional capacity. They preferred a minimum use of medication, and they did not want to use any drugs unnecessarily. The interviewees reported their concern about polypharmacy and contraindications: "I do not want to take any more drugs than necessary, I have always been particular about drug."

Some of the interviewees were concerned to have so many drugs, and they would have wanted to discard some of the drugs in order to decrease the amount of medication. The participants did not report self-perceived contraindications, but they felt a mental need to decrease the amount of medica- tion. When having all their drugs on the table, they described how they felt that there were simply too many drugs: "I think that there is an awful amount of drugs." The interviewees thought that doctors today prescribed drugs for every little ailment, all too easily.

Pharmaceutical Care at Home. Those interviewees who coped independently with their pharmaceutical care were satisfied with their situation and grateful for still being able to do so. In many cases, they had had the same medication for years and this worked well for them. They wanted to maintain independent pharmaceutical care. This was motivated by a will to control own life: "So far it has been alright, when I use the dispenser I know if I have taken my pills, so I can control my medication," "I think my situation is good because I still can take care of my medication," and "I am happy now because I still can dispense my own medicines."

One interviewee wanted to fill her dispenser independently, but the doctor thought that a home nurse should do it: "Earlier I took care of my drugs. Then I was in a hospital and the doctor there informed the home nursing services that somebody has to distribute my medication. Because I had done that by myself for many years, I suggested that the home nurse could come and dispense the drugs for one week and then I could dispense the second week and show her that I had done it right." Eventually, the home nurse dispensed the drugs for one week, and the interviewee dispensed the drugs for other weeks, and the dispenser was checked by the nurse.

The independently coping older people reported that home nursing services were "a last resort" for them. They felt it was a relief to know that they could ask for home nursing services when they could not longer independently cope with pharmaceutical care.

The interviewees sometimes changed their dosages independently. In this way, they wanted to show control over their pharmaceutical care although, in principle, they followed the doctors' orders. They reported they knew best their own feelings and that it was possible to adjust medication according to one's feelings. For example, diuretics were drugs that people did not take or they postponed the administration of the drug if they had an appointment on the same day.

Home nursing services were in charge of some older people's pharmaceutical care. These interviewees felt that pharmaceutical care was the responsibility of the nurses and doctors, and they just took all the drugs that were given to them. These respondents thought that when home nursing services took care of pharmaceutical care, they did not need to know anything about the medication. They 
were merely happy that somebody else carried out pharmaceutical care for them because they were no longer capable of doing so. At the same time, these interviewees felt that the home nurses were very busy, and there was no time to talk about pharmaceutical care. During the visits, they preferred to talk about their general condition rather than medication. They were not always aware of their medication, but they emphasized personal alertness with pharmaceutical care: "Substitute nurses do not always dispense the right medication. I always check the dosage after them."

\section{Discussion}

Some of the interviewees had a very good knowledge about their pharmaceutical care, but there were also people who had none. This was an alarming result since we know that if people have precise knowledge about their pharmaceutical care, it has helped them to commit to successful care $(1,7-9,13)$. Older people who were ignorant of their pharmaceutical care were recipients of home nursing services, and the nurses took care of their medication. However, one should remember that many home help clients only receive home nursing once a week when the nurse comes to fill the dispenser. After that, pharmaceutical care depends on the older people's abilities. Poor social support is a difficult problem to resolve (18). In this study, 3 interviewees lived together with a spouse or a son. It is possible that this can affect the results, if those family members were responsible for the older people's pharmaceutical care. Nonetheless, health care providers as well as family members can provide the assistance to help older people resolve difficulties in obtaining needed medications.

It seems that there is not enough pharmaceutical information available or it does not reach older people. Careful oral and written guidance would help older people to understand the significance of pharmaceutical care and best benefit from medication, for part of the older people's bed-days in hospitals are due to the problems of pharmaceutical care (19). Guidance on pharmaceutical care can be promoted among older people and their families through improved cooperation between health care providers and pharmacies. The development of older people's care requires openness to new methods and multiprofessional cooperation $(1,3,10)$. Regular medication assessments through multiprofessional cooperation should be a permanent part of older people's care (3). In addition, it is important to carefully plan what kind of guidance older people need in their pharmaceutical care and how the guidance sessions best support the various stages of care.
The interviewees had a positive attitude toward their pharmaceutical care and they preferred a minimum use of medication. The result concurred with earlier studies that showed positive attitudes to medication among older people (5-7). Some of the interviewees felt they had too many drugs and they expressed concern about polypharmacy and contraindications. Similar results have been reported earlier (5). Compared to previous studies, the new thing about the interviewees' reports was that the people in charge of their own medication were satisfied with the situation and they were grateful that they still were able to manage their pharmaceutical care. They also hoped to continue their pharmaceutical care for as long as possible. The results showed the possibilities of older people to influence their pharmaceutical care. Thus, the resources of older people have been recognized and utilized in pharmaceutical care, and that enhances the success of medication and people's commitment to it (20). The results offer new knowledge about the significance of pharmaceutical care at home for older people and about the meaningful ways of pharmaceutical care at home. By listening to and utilizing older people's experiences, we can recognize the factors that promote their inclusion in their pharmaceutical care.

Traditionally, medical professionals have been responsible for pharmaceutical care. Today people are encouraged to take more responsibility for their own care because it will lead to better results than traditional expert-oriented methods $(10,21,22)$. Supporting the self-care of older people regarding their personal wishes and accepting their solutions are the best way to successful care $(21,22)$.

One very interesting and important result of the study was that independently organized pharmaceutical care strengthened the older people's sense of control over their lives. Sense of control is a key resource in old age. As a resource, it means the individual experience of influencing the significant events of one's life and ability to control the changing situations in life (23-25). The more people feel capable of coping with life changes, the more they have resources to confront losses related to aging, such as deteriorating health and functional capacity $(26,27)$. The actions of care professionals should support the expectations and resources of older people. By involving older people in their pharmaceutical care and decision-making, the professionals can improve individuals' trust in their personal resources. It is important that health care providers recognize the risks concerning expert-orientation when planning the pharmaceutical care of older people. They may make decisions concerning care based on what they think and believe to be best for older people and what they think older people want (28). 
Trustworthiness. Findings in this kind of study can be evaluated in terms of trustworthiness, i.e., dependability, credibility, transferability, and confirmability (29). The dependability of the results is enhanced by describing the strategies and the procedure of the analysis in such a way that the reader can follow it. The credibility of the study is increased by the researchers' experiences in older people's care. The researchers have worked in older people's care. These experiences helped in the whole process, especially in interviewing the participants and in asking follow-up questions. The researcher met the interviewees on one occasion only. However, it was quite clear that the interviewees enjoyed talking about their experiences and valued the interest shown in their opinions. The small number of participants who were sampled from only one region in Finland means that the results have only limited generalizability. Although the findings cannot be generalized, they can be transferred to similar situations. In qualitative data analysis, it is usually recommended to have two or more researchers doing the analysis and seeking the congruence (30). In this study, the data were analyzed by the researcher who collected the data. An analysis by two researchers may have confirmed the results in the study. However, the confirmability of the analysis was affirmed through discussions with the research group during the analysis process. In addition, the confirmability of the findings was affirmed through discussions with three experienced nurses in older

\section{References}

1. Murray MD, Callahan CM. Improving medication use for older adults: an integrated research agenda. Ann Intern Med 2003;2:425-9.

2. Alic A, Pranjic N, Ramic E. Polypharmacy and decreased cognitive abilities in elderly patients. Med Arh 2011;65:102-5.

3. Jyrkkä J. Drug use and polypharmacy in elderly persons. [dissertation]. University of Jyväskylä, Finland; 2011. Available from: URL: http://epublications.uef.fi/pub/urn isbn 978-952-61-0385-3/

4. Lampela P, Hartikainen S, Sulkava R, Huupponen R. Adverse drug effects in elderly people - a disparity between clinical examination and adverse effects self-reported by the patient. Eur J Clin Pharmacol 2007;63:509-15.

5. Lumme-Sandt K, Hervonen A, Jylhä M. Older people and the diverse worlds of medical drug use. Soc Science Med 2000;50:1843-50.

6. Linjakumpu T. Drug use among the home-dwelling elderly. [dissertation]. University of Oulu, Finland; 2003. Available from: URL: http://herkules.oulu.fi/isbn9514271025/

7. Ulfvarson J. Drug treatment of elderly - the need for changing behaviour among providers and patients. [dissertation]. Stockholm: Karolinska institutet, Sweden; 2004. Available from: URL: http://diss.kib.ki.se/2004/91-7140-010-9/

8. Savikko N, Pitkälä K. Hoitoon sitoutumisen merkitys ja haasteet. (The importance and challenge of adherence to care.) TABU - Lääkeinformaatiota lääkelaitokselta 2006; 5:4-7. [In Finnish] people's care. The research group members and experienced nurses recognized the results as manifested in the data analysis. In addition, the experiences of the participants were very similar.

\section{Conclusions}

Summarizing, this study revealed issues that help to understand the experiences of older people concerning pharmaceutical care at home. The study offers new knowledge about the significance of older people's individual pharmaceutical care at home. By listening to and utilizing older people's experiences, we can recognize the factors that promote the independent coping and inclusion of older people in their pharmaceutical care. Many factors, such as medication awareness, can be influenced with quite small changes. Successful pharmaceutical care guarantees care according to plan, it increases knowledge, and in this way, it provides security for older people. It will probably also decrease health care costs, as it will become possible to prevent the deterioration of illnesses.

\section{Acknowledgments}

This research received the financial support to EVO funding to the Turku City Hospital, Finland. The authors also would like to acknowledge Ilkka Sýren for the revision of the English language for this paper.

\section{Statement of Conflicts of Interest}

The authors state no conflict of interest.

9. Schüz B, Marx C, Wurm S, Warner LM, Ziegelmann JP, Schwarzer R, et al. Medication beliefs predict medication adherence in older adults with multiple illnesses. J Psych Res 2011;70:179-87.

10. Eloranta S, Welch A, Arve S, Routasalo P. A collaborative approach to home care delivery for older clients: perspectives of home care providers. J Interprof Care 2010;2:198-200.

11. Haynes RB. Interventions for helping patients to follow prescriptions for medications. Cochrane Database of Systematic Reviews, Issue 1; 2001.

12. Pitkälä K, Routasalo, P, Airaksinen M. From adherence to treatment to support of self-management. In: Saarinen A, Tamminen T, editors. Medicines and health. Helsinki, Finland: Lääketietokeskus Oy; 2008. p. 121-7.

13. Sorensen L, Stokes J, Purdie D, Woodward M, Roberts M. Medication management at home: medication-related risk factors associated with poor health outcomes. Age Ageing 2005;34:626-32.

14. Seidman IE. Interviewing as qualitative research: a guide for researchers in education and the social sciences. 2nd ed. New York: Teachers College Press; 1998.

15. Arve S, Lavonius S, Savikko N, Lehtonen A, Isoaho H. Social functioning and survival: a 10-year follow-up study. Arch Gerontol Geriatr 2009;48:137-41.

16. Miles M, Huberman A. Qualitative data analysis. 2nd ed. Sage, CA: Thousand Oaks; 2001.

17. Cavanagh S. Content analysis: concepts, methods and ap- 
plications. Nurs Res 2000;4:5-16.

18. Murray MD. Implementing pharmacy practice research programs for the management of heart failure. Pharm World Sci 2010;32:546-8.

19. Ulfvarson J, Adami J, Bardage C, von Bahr C, Wredling R. Drug use and perceived health in recently hospitalized older people. Br J Community Nurs 2005;10:469-74.

20. Bilotta C, Lucini A, Nicolini P, Vergani C. An easy intervention to improve short-term adherence to medications in community-dwelling older outpatients. A pilot non-randomised controlled trial. BMC Health Serv Res 2011;11:158.

21. Routasalo P, Airaksinen M, Mäntyranta T, Pitkälä K. Supporting a patient's self-management. Duodecim 2009;125: 39-47. [In Finnish]

22. Routasalo P, Airaksinen M, Mäntyranta T, Pitkälä K. Pitkäaikaissairaan omahoidon opastus. (Guidance of the selfcare for people with chronic disease.) Suomen Lääkärilehti 2010;65:1917-23. [In Finnish]

23. Eloranta S, Routasalo P, Arve S. Personal resources supporting living at home as described by older home care clients. Inter J Nurs Prac 2008;14:308-14.

Received 24 October 2011, accepted 30 November 2011
24. Reichtadt J, Depp CA, Palinkas LA, Folsom DP, Jeste DV. Building blocks of successful aging: a focus group study of older adults' perceived contributors to successful aging. Am J Geriatr Psychiatry 2007;15:194-201.

25. Ravanipour M, Salehi S, Taleghani F, Ali Abedi H, Schuurmans MJ, Jong A. Sense of power among older people in Iran. Educ Geront 2008;34:923-38.

26. Häggman-Laitila A, Pietilä AM. Life control and health in view of qualitative and quantitative research. Inter J Nurs Pract 1998;4:103-12.

27. Uotinen V, Suutama T, Ruoppila I. Age identification in the framework of successful aging. A study of older Finnish people. Int J Aging Hum Dev 2003;56:173-95.

28. Chevannes M. Social construction of the materialism of needs assessment by health and social care professionals. Health Social Care Community 2002;10:168-78.

29. Holloway I, Wheeler S. Qualitative Research in Nursing. 2nd ed. Oxford: Blackwell Publishing Company; 2002.

30. Barbour RS. Checklists for improving rigour in qualitative research: a case of the tai wagging the $\operatorname{dog}$ ? BMJ 2001;322: 1115-7. 